\title{
Eğitimde Yeni Yönelimlerin Değerlendirilmesi ve Eğitim 4.0
}

\author{
Ercan Öztemel \\ Marmara Üniversitesi, Mühendislik Fakültesi, Endüstri Mühendisliği Bölümü, İstanbul
}

\begin{abstract}
Özet
Dördüncü Endüstriyel devrim olarak adlandırılan ve kısaca "Endüstri 4.0" olarak bilinen teknolojik gelişimler insan hayatı üzerinde önemli değişimlere yol açmaktadır. Yaşamın her alanında yeni sistemler, yaklaşım tarzları, yönetim sistemleri ortaya çıkmaktadır. Toplumların, önceleri tarım toplumundan endüstri toplumuna oradan enformasyon toplumuna oradan da bilgi toplumuna evrilmesi sadece imalat sistemlerinde değil aynı zamanda eğitim, sağlık, çevre gibi hizmet üretiminin kaçınılmaz olduğu alanlarda da kendisini göstermektedir. Literatürde sağlık 4.0, çevre 4.0, su 4.0, lojistik 4.0, eğitim 4.0 gibi kavramlara rastlamak mümkündür. Bu çalışmada özellikle eğitim 4.0 kavramı irdelenecek ve bilinen eğitim sistemlerinde olası değişimlere dikkat çekilecektir. Eğitim 4.0 ile bilinen eğitim sistemleri teknolojik gelişmeler ile bütünleşmekte ve inovasyon ağırlıklı bir yapıya bürünmektedir. Bu sebeple çalışmada, eğitim 4.0 sisteminin bileşenleri açıklanarak bu kapsamda sistemsel dönüşümün nasıl gerçekleştirilebileceğine yönelik bilgiler de verilecektir.
\end{abstract}

Anahtar Kelimeler: Eğitim Teknolojileri, Eğitim 4.0, Endüstri 4.0

\section{Giriş̧̧}

Endüstri 4.0 kavramı ile toplumlarda hızlı bir dijital dönüşüm tetiklenmektedir. Bu kapsamda olası gelişmeler incelendiğinde açık olarak görülmektedir ki dijital hâkimiyet bir taraftan endüstriyel yaşamda her an kendisini daha fazla hissettirirken diğer yandan toplumsal anlamda önemli gelişmelere yol açmaktadır. Araştırmacılar Endüstri 4.0 uygulamalarının toplumda yol açacağı gelişmelere dikkatleri çekmektedir. Örnek olarak Oztemel (2017), Davies ve diğerleri (2017) incelenebilir. Tarihsel süreç içerisinde sanayileşme hareketi buhar makinesinin icadı ile (birinci devrim) başlamış, elektriğin icat edilmesi neticesinde seri imalat yoğun (ikinci devrim) bir şekilde devam etmiştir. Bilişim teknolojisindeki gelişmeler ve otomasyon (üçüncü devrim) endüstriyel toplumlarda beklentilerin çok üzerinde bir dönüşüm oluşturmuş; bu değişimin etkisi günümüze kadar gelerek dijital ve otonom sistemlerin hâkim olduğu (dördüncü devrim) bir dünyaya hızla yol alınmıştır. Bu konuda yoğun araştırmalar yapılmaktadır. Liao ve diğerleri (2017) örnek çalışmaların bir değerlendirmesini sunmuştur.

Dijital imalat (otomasyon, veri alışverişi, üretim teknolojileri), bütünleşmiş iletişim ağ 1 (nesnelerin interneti), siber fiziksel sistemler, akıllı fabrikalar (esneklik, hız, verimlilik) kendisini gösterdikçe, üretilen ürünlerin ve sunulan hizmetlerin de nitelikleri değişmektedir. Boyut-

*Yazışma Adresi / Address for Correspondence:
Ercan Öztemel, Email: ercanoztemel@gmail.com
Geliş Tarihi / Received Date: 21.01.2018
Kabul Tarihi / Accepted Date: 10.01 .2018
Doi: $10.26701 /$ uad.371662

lar küçülmekte ancak marifetler büyümektedir. Kendi kendisine kararlar verebilen, kullanıcısı ile iletişim kurarak destek üreten, kendi yapısındaki iyi kötü gelişmelere dikkat çeken ürünler ile bir taraftan yaşam kolaylaşırken diğer taraftan daha fazla makinelere bağlı bir yaşam oluşmaya başlamıştır. İnsanlara yeni imkânlar sunulur iken, robotların insanları işsiz bırakacağı ve insanlara karşı oluşturacağı engellerden bahsedilmektedir.

$\mathrm{Bu}$ gelişmelerin önüne geçilmesinin mümkün olamayacağı açıtır. Olası negatif etkilerden daha çok pozitif katkılar ve faydalar söz konusudur. Faydaların öne çıkartılarak negatif etkilerin minimize edilmesinin en etkin yollarından birisi eğitim sistemlerinin etkin olarak yürütülmesidir. Bu da doğal olarak eğitim sistemlerinde de dijital bir dönüşümü tetiklemektedir. Sözkonusu dijital dönüşüm, Eğitim 4.0 olarak isimlendirilmektedir (Puncreobutr, 2016).

\section{ENDÜSTRI 4.0}

Bilgi toplumunun temel sütunlarından birisi olan bilişim sistemleri ve ilgili teknolojik imkânlar makinelerin yorum yapabileceğini, problem çözebileceğini, ilişki kurup karar verebileceğini, öğrenebileceğini, bilgisayarların normal koşullarda çözemediği karmaşık problemlere çözümler üretebildiğini, kelimeleri anlayabildiğini, merdiven çıkabildiklerini, top oynayabildiklerini, sorulara cevap verebildiklerini, birbirleri ile haberleșebildiklerini, olayları algılayıp önceliklendirebildiklerini açık olarak göstermektedir. Bununla birlikte bazı konularda henüz tam olarak istenilen düzeye gelinmese de bilgisayarların ve makinelerin birbirleri ile konuşabilecekleri, aynı ama- 
ca yönelebilecekleri (amaç/sensor modellemesi), sosyalleşebilecekleri, yardımlaşabilecekleri, birbirlerine destek olabilecekleri (duygusal zeka), birbirlerine olayları öğretebilecekleri, hatta ARGE çalışmaları dahi yapabilecekleri konusunda önemli gelişmelere şahit olunmaktadır. Dördüncü endüstriyel devrim olarak tanımlanan bu gelişmelerin en temel bileșenleri șu şekilde sıralanabilir:

- Otonom robotlar: Kendi başlarına hareket edebilen, karar verebilen, sorun çözebilen imalat ortamında yaygınlaştırılan robotlar.

-Zeki bilișim ağı: Makinelerin birbirleri ile insanlar ile ve yazılımlar ile haberleşmesini sağlayan ve veri trafiğini kontrol ederek yönetebilen bilişim ağı.

- Sistem entegrasyonu: Tüm sistemlerin birbirleri ile bütünleşik olarak çalışması ve bağımsız karar verebilen ancak bağımlı çalışmak durumunda olan imalat sistemlerinin devreye alınmasıdır.

- Siber fiziksel sistemler: Tüm iletişimi ve sistemlerin bütünleștirilmesini mümkün kılan siber sistemler.

- Siber güvenlik sistemleri: Tüm iş ve işlemlerin bilişim ortamında güvenli bir şekilde yürütülmesine olanak veren sistemlerin çalışmasında her türlü siber saldırının önüne geçecek önleyici yeteneği yüksek sistemler.

- Nesnelerin interneti: İmalat ortamındaki sistemler başta olmak üzere toplumun her kesiminde birbiri ile haberleșen nesnelerin ve bunların iletişimini mümkün kılacak veri değişim protokollerinin devreye sokan internet.

- Büyük veri analizleri: Her yll bir önceki yllın iki katı kadar yeni veri üretilmektedir. Büyük veri üzerinde yapılan zeki analizler ile otomatik olarak karar vericilere gerekli bilgilerin sağlanmasıdır. Doğru bilginin doğru zamanda doğru yerde olmasını temin etmektir.

- Bulut bilişim: Eskiden olduğu gibi büyük paralar verip yazılımlar satın almak yerine bulut bilişim teknolojisi ile hem saklama sistemleri hem de yazilım kullanma imkânları oldukça küçük maliyetler ile karşılanabilecektir. "Kullandığın kadar ödemek" mümkün olabilecektir.

- Benzetim ve Artırılmuş gerçeklik: Benzetim orta$\mathrm{m}$ ile gerçek ortam birbiri ile bütünleşik bir şekilde kullanılabilecektir. Arızalanan sistemler gözlüklerde sanal modelleri üzerinden gösterilen biçimde gerçek sistem üzerinde tamiratı yapllabilecektir. (Bu biraz açılabilir mi?)

- Eklemeli imalat ve 3 Boyutlu yazıcılar: 3 boyutlu yazıclar ile sadece model bilgilerinin bilgisayara girilmesi ile istenilen nitelikte ve ebatlarda fiziksel ürünlerin üretilebilmesidir.

- Önleyici bakım: Yeni endüstriyel dönüşümde makinalar sürekli çalışmak durumunda kalacaklardır. Bu da doğal olarak makinaların bakımlarının daha titiz gerçekleștirilmesini ve oluşabilecek olumsuzlukların önceden görülerek tedbirler olușturulmasını gerekli kılacaktır.

Endüstriyel dönüșüm sadece imalat ortamının zekileștirilmesi ve bilişim ağının esnekliği, üretimin hızı vb. yenilikleri getirmemektedir. Aynı zamanda üretilen ürünlerde "zeki ürün" olma nitelikleri artmaktadır. Kișiselleștirilmiş ürünler pazarda kendisini göstermeye bașlamıștır bile. Her ürün bir taraftan kişisel kimlik kazanırken diğer taraftan bir gözlemci olarak görev yapabilmektedir.

İmalat ortamında kullanılan robotların da boyutları küçülmekte ama yaptıkları işlerin sayısı ve nitelikleri artmaktadır. Artık robotlar insanlar ile de etkileşimli çalışabilmektedir. Robotlar, ürün hafızasından ağırlık, büyüklük ve tutma noktaları hakkında bilgiyi elindeki anten yardımıyla okuyabilmektedirler. CPPS (Siber fiziksel İmalat Sistemleri) altında üretilmiş parçalardan komutlar alarak çalışmaktadırlar.

\section{EĞiTim 4.0}

Eğitim 4.0, diğer alanlarda olduğu gibi eğitim dünyasında da dijital dönüşümün gerçekleștirilmesi anlamına gelmektedir. Endüstri 4.0 anlayışına paralel olarak eğitim dünyasının 4 ana dönüşümü yaşadığını söylemek yanlıș olmaz. Wallner ve Wagner (2016), Puncreobutr (2016), Rosik (2017), Fisk (2017) gibi araștırmacılar bu konuya dikkatleri çekmektedir. Genel hatları ile eğitim dünyasındaki değişim ve dönüşümün aşağıdaki gibi bir süreci izlediği görülmektedir.

Eğitim 1.0: Doğal olarak tarım toplumunun ihtiyaçlarına cevap verecek nitelikte eğitimlerin gerçekleştirilmesi şeklinde tanımlanmaktadır. Tarım toplumlarında bilgi öğretmenden öğrenciye kavramlar yardımı ile aktarılırdı. Olayları ve ilgili bilgileri öğrenebilmek için kapsamlı çalışmalara ihtiyaç duyulmaktaydı. Öğrenciler daha çok hocalarını izlemek ve onların uyguladıkları yöntemleri uygulamak durumunda idi. Yeni metotlar geliştirmek temel amaçlardandı.

Eğitim 2.0: Endüstriyel toplumlarda eğitim sistemlerinin içeriklerinde de önemli bir dönüşüm yaşanmış, daha çok sanayi kuruluşlarının temel ihtiyaçlarını karşlayacak teknolojilerin ve teknolojik araçların geliștirilmesi esas olmaya başlanmıștır. Özellikle iş hayatında kullanılacak teknolojilerin geliștirilmesi önemli bir eğitim bileșeni olmaya bașladı. Özellikle kütle üretimini tetikleyecek gelişmeler önemli bir eğitim motivasyonu olmaya başladı. Pooworawan, (2015)'e göre bu dönemde eğitim kurumları bir fabrika, öğrenciler ise bu fabrikalarda üretilen ürünler olarak görülmeye başlanmıştır. Eğitim içerikleri eğitimden geçirilecek öğrencilerin temel niteliklerine ișaret etmiştir. Sınavlar eğitim sisteminin kalite kontrolü, diplomalar ise garanti belgesi olarak görülmeye başlamıştır. Bu aşamada daha çok Bloom tarafından tanımlanmış olan öğrenme sürecinin eğitim sistemlerini yönlendiren bir güç olduğu 
görülmektedir (Bloom et al.,1964).

Ĕgitim 3.0: Toplumun enformasyon odaklı yapılanması başlayınca doğal olarak eğitim sistemleri de "teknoloji toplumu"nun ihtiyaçlarına cevap verebilecek şekilde yapılanmaya başladı. Bu dönemin temelinde "kendi kendine öğrenme" olgusu ortaya çıktı. Dijital medyanın kullanılmasıyla internet başta olmak üzere sosyal medyanın kendisini eğitim sistemlerinde ağırlıklı olarak hissettirdiği dönem başladı. Bilgisayar destekli ve karşılıklı etkileşimli eğitim sistemleri ortaya çıktı. Bu dönemde ortaya çıkan diğer önemli bir dönüşüm ise öğrencilerin bilgiyi tüketenler olmak yerine "bilgiyi üretenler" olarak eğitilmeleridir. Bu aşamada özellikle eğitim sistemlerinin kalite güvencesinin sağlanması temel olmaktadır. Bologna süreci (Crosier D. and Parveva, 2013) ile başlayan çok uluslu ortak eğitim programlarının ve sistemlerinin devreye alınması söz konusu olmuştur.

Eğitim 4.0: Endüstri 4.0 dönüşümü ile eğitim sistemlerinde de inovasyonun hâkim olmaya başladığını söylemek yanlış olmaz. Daha doğrusu, önümüzdeki yıllarda inovasyon ağırlıklı eğitim gerçekleştiren eğitim kurumlarının başarılı olması söz konusu olabilecektir. Eğitim kurumları Aslangilay'ın (2016) dikkatleri çektiği gibi inovasyonu sadece küreselleşmenin etkisi ile dünya çapında rekabet gücünü artırmayı sağlamakla sınırlı görmeyip, bununda ötesine geçerek eğitim sisteminin temel bileşenlerinden birisi olarak görmek durumunda kalacaklardır.

Ayrıca Eğitim 4.0 ortamında görselleştirilmiş eğitim öğretim araçlarının yoğun olarak kullanılması kaçınılmaz bir gereksinim olacaktır. Toplumsal dönüşüme ayak uyduracak yeni teknolojilerin eğitilmesi temel ihtiyaçlardan sayılacaktır. Bu dönemde "yaşam boyu öğrenme" eğitim kurumlarının temel misyonları arasında yer alacaktır. Bilgi kadar liderlik, işbirliği, yaratıcılık, dijital okuryazarlık, etkili iletişim, duyusal zeka, girişimcilik, global vatandaşlık, takım çalışması ve problem çözebilme kabiliyeti gibi yeteneklerin geliştirilmesi ve kabiliyetlerin kalitesinin garanti edilmesi de temel öğrenme kazanımı sayılacaktır. Bu açıdan bakıldığında Eğitim 4.0 sadece eğitim sistemi olarak görülmemelidir. Kritik analitik düşünme, yenilikleri ortaya çıkartmak (inovasyon), verimlilik, sorumluluk ve çok kültürlü bilgi paylaşımı, kariyer geliştirme gibi unsurlara odaklanmak kaçınılmaz olacaktır.

Endüstri 4.0'ın gerektirdiği her alanda tasarlayacak, geliştirecek, üretecek ve üretilen teknolojiyi kullanabilecek insan gücünün eğitimi kaçınılmaz bir gerçektir. Endüstri 4.0'ın gerçekleri; üst düzey düşünme becerilerine sahip bireylerdir, bilmenin yetmeyeceği, düşünmenin zorunlu hale geleceği yöntemlerdir. Dünya problemlerini doğru hissedecek ve tanımlayacak (eleştirel düşünme), çözümü için yenilikçi fikirler üretecek (yaratıcı düşünme), çözüm için doğru yöntem ve teknikleri kullanacak (bilimsel ve analitik düşünme) bireylerin her alanda yetiştirilmesi büyük önem taşımaktadır. Bu durum okulöncesi, ilköğretim, ortaöğretim, yükseköğretim ve yaşam boyu öğretim de ol- mak üzere çok geniş bir perspektifte birbirleriyle entegre ve etkileşimli olarak düşünülmesi, planlanması, tasarlanması ve uygulanması gereken bir konudur.

Eğitim 4.0 yaklaşımında genel olarak yapılandırmacı eğitim sistemlerinin uygulanacağı belirtilmekte ve Bloom taksonomisinin ötesine geçilerek özellikle aşağıda açıklanan 3 alana dayalı bir öğrenme sürecinin uygulanacağı tanımlanmaktadır Gomaratat (2015).

- Anlamayı düzenleyen 3R (Recalling- Hatırlama, Relating- İlişkilendirme, Refining- Rafine etme)

- Araştırmayı tetikleyen 3I (Inquiring- Sorgulama, Interacting- Etkileşim, Interpreting- Yorumlama)

- Netice üretmeye dayalı 3P (Participating- Katılımcı olma, Processing- İşleme, Presenting- Sunma)

Öğrencilere bu yetenekleri kazandırabilmek için görsel öğrenme, kişiselleştirilmiş eğitim sistemleri, oyun ve senaryo tabanlı öğrenme, proje bazlı problem çözme, artırılmış gerçeklik gibi yaklaşımların kullanılmasının gerekli olacağına işaret edilmektedir (Nedeva and Dineva, 2012).

Başta yükseköğretim akademik camia olmak üzere, eğitim sistemlerinde hedeflenen kazanımlara ulaşmak amacıyla üniversitelerde eğitim kalitesini arttırmak, öğretmen adaylarını teknoloji ile bütünleştirmek, onlarla inovatif ürünler geliştirmek, dijital okuryazarlığ geliştirmek gibi konularda eğitim araștırmalarına odaklanmak zorunluluğu bulunacaktır. Geleceğin bu tür eğitim ihtiyaçlarını karşılamak üzere eğitim sistemlerinde de önemli değişimler yaşanacaktır. Yukarıda kısmen açılamaya çalışıldığı gibi genel hatları ile öğrenmeden daha çok inovasyon ağırlıklı bir yaklaşım öne çıkacaktır. Öğrenmenin giderek çocuklar için önemli bir aktivite olmaktan çıkarak hayat boyu öğrenmenin önemli olacağ günlere doğru süratle yol alınmaktadır. İlgili literatürün incelenmesi neticesinde eğitim 4.0 kapsamında oluşacak olan temel değişim ve dönüşüm noktaları aşağıda maddeler halinde özetlenmiştir:

1. Eğitim öğrenim faaliyetleri farklı mekânlarda, farklı zamanlarda ve farklı araçlar kullanılarak olabilecektir. Her yerde ve her zaman eğitim/öğrenim anlayıșı hâkim olacaktır. Bireyler kendi anlayış ve kavrayışları doğrultusunda uzaktan eğitimler alabileceklerdir. Teorik bilgiler sınıf dışında elde edilebilecektir. Pratik bilgiler ise yüz yüze eğitimin temel taşlarını oluşturacaktır.

2. Öğrenciler kendi kabiliyet ve yeteneklerine uyarlanabilir eğitim sistemleri üzerinden kișiselleștirilmiș eğitimler alabileceklerdir. Öğrencilerin öğrenme hıları ve durumlarına göre eğitimin içerikleri de zenginleştirilebilecektir. Öğrenciler bir konuyu anlamakta zorluk çekerler ise o konunun üstesinden gelinceye kadar tekrar tekrar eğitimleri alabileceklerdir. Bireysel öğrenme 
becerileri ile doğru orantılı olarak sürekli cesaretlendirileceklerdir. Böylece öğrencilerin öz güven kazanmaları sağlanmış olacaktır. Ayrıca öğretmenler de hangi öğrencilerin hangi konularda daha fazla desteği olduğunu görebilecekleri araçlara sahip olacaklardır. Diğer bir deyişle, öğrencileri eğitim sistemine uydurmak yerine sistemi öğrencilerin kabiliyet ve yeteneklerine göre șekillendirmek mümkün olabilecektir.

3. Her ne kadar derslerin amacı öğrenciyi belirli bir noktaya götürmek olsa da her öğrencinin hedeflenen noktaya erişmesi için izleyeceği yol farklı olabilecektir. Öğrenciler kişiselleştirilmiş öğrenme araçları ile kendileri için uygun olduğunu düşündükleri araçlar ile kendi öğrenme süreçlerini tasarlayabileceklerdir. Öğrenciler Kendi tercihleri ile serbest olarak tercihleri doğrultusunda șekillendirilmiș yani kendi eksikliklerini giderebilecekleri eğitim programı ve araçları ile esnek öğrenme gerçekleștirebileceklerdir. Harmanlanmıs öğrenme, sınıfsız öğrenme, kendi cihazları ile öğrenme gibi yeni yaklaşımlar ile öğrenme önemli olacaktır.

4. Öğrenciler kendilerini gelecekteki serbest ekonomik ortamlarda bağımsız çalışmaya hazırlamak durumunda kalacaklarından proje bazlı öğrenme ve çalışma gerçekleştirmek durumunda kalacaklardır. Yani yetenek ve kabiliyetlerini kısa sürede nasıl uygulayacaklarını öğrenmek durumunda kalacaklardır. Kurumsal ve organizasyonel zaman yönetimi öğrencilerin geleceğe hazırlamaları için öğrenmeleri gereken temel gereksinimlerden birisi olacaktır.

5. Teknolojik gelişmelerin ışı̆̆ında özellikle insan bilgi ve uzmanlığı gerektiren, yüz yüze etkileşime dayalı bir öğrenme ortamı oluşturulabilecektir. Derslerin temel teması alan bilgisi ve tecrübeye odaklanacaktır. Öğrencilere daha çok gerçek dünya problemlerini çözebilecekleri yetenekler kazandırmak üzere eğitimler verilecektir. Bu da daha çok STAJ, MENTOR Projeleri, ve TAKIM çalışması, İSBİRLİĞİ odaklı yaklaşımlar ile eğitim/öğrenim faaliyetlerinin zenginleştirileceğini göstermektedir.

6. Günümüzde cehaleti ortadan kaldıran en önemli 3 göstergeden birisi matematik bilgisidir. Gelecekte manuel matematik işlemlerinin artık cehaleti önleyen unsurlardan görülmeyeceği açıktır. Bilgisayarlar her türlü istatistiki analizleri yapabilecek, verileri analiz edebilecek ve geleceğe yönelik tahminler gerçekleştirebilecektir. İnsanların yapması gereken daha çok bu verileri yorumlayabilmek olacaktır. Cehaleti ortadan kaldıran ve okuryazar sayılmanın en önemli göstergesi artık teorik bilgileri numerik verilere uygulayıp (veri analizleri gerçekleștirip) bu verilerden geleceğe yönelik trendleri ortaya çlkartma kabiliyeti olacaktır. Öğrencilerin büyük veri konusunda yoğun olarak eğitilmeleri ve analiz kabiliyetlerinin geliştirilmiş olması gerekecektir.

7. Sınav şekilleri de tamamı ile değişecektir. Artık Soru ve Cevap uygulamasından vazgeçilecektir. Öğrenciler konuları en sonuna kadar ezberleyip sınavdan sonraki gün unutmaktan kurtulacaklardır. Öğrenme süreci boyunca bilgileri ölçülecek ve bilgileri, sahada uygulama kabiliyetleri, çalıștıkları projelerin performansı ile test edilecektir. K1sacası SINAV yerine DURUM DEĞERLENDİRE kavramı gündemde olacaktır.

8. Öğrenciler ders içeriklerini oluşturma konusuna her geçen gün daha fazla dahil olacaklardır. Öğrenciler ve öğretmenlerin birlikte hazırladıkları içerikler ile güncel, modern ve gerçekçi içeriklere ulaşılabilecektir. Öğrenim programlarının en önemli girdisi öğrencilerin içerikler ile ilgili kritikleri olacaktır.

9. Mentor kullanma her geçen gün daha önemli olacaktır. Öğrencilerin öğrenme süreçleri daha bağımsız olacak o nedenle mentor kullanma öğrencinin başarısında önemli bir katkı üretecektir. Eğitim uzaktan gerçekleştirileceğinden öğretmen ve eğitim kurumları akademik performans için daha önemli olacaktır. Eğitim 4.0 dünyasında sanal mentorlar aktif olarak kullanılacaktır.

10. Internet üzerinden tüm kurslara ve derslere erişim söz konusu olabilecektir. Öğrencilerin en uygun şekilde öğrenmeleri için web arayüzleri ve erișim sistemleri gerçekleştirilecektir.

11. Tüm zamanların teknolojilerini etkileyecek yeni teknolojiler gelişmektedir. Bu teknolojilerin eğitim sistemlerinin de bir parçası olması söz konusu olacaktır. Eğitim 4.0 bu teknolojileri hem eğitim sistemlerinin ve araçlarının oluşturulmasında kullanacak hem de öğrencilerin öğrenmesi için eğitim programının bir parçası yapacaktır. Genel Hatları ile 13 teknolojinin aktif olarak gündemde olacağ öngörülmektedir. Bunlardan bazıları gündeme gelmiştir bile:

1. Büyük veri analizleri

2. İmplante teknolojiler

3. Bulut Bilișim

4. Mobil internet

5. Nesnelerin interneti

6. Bilgi otomasyonu

7. İleri robot teknolojileri

8. Otonom cihazlar

9. Yeni nesil genler (Gen bilimi)

10. Enerji depolama ve yenilenebilir enerji

11. 3 boyutlu bask1

12. İleri ve zeki malzemeler

13. İnsansız araçlar

14. Bitcoin ve Blockchain teknolojileri (akıllı 
kontrat oluşturma, bilgi güvenliği, gizlilik sağlama teknolojisi)

$\mathrm{Bu}$ anlatılanlardan hareketle üniversitelerin de eğitim/ öğretim stratejilerinde değişiklikler olacaktır. Bunlar arasında aşağıdakileri saymak mümkündür:

- Dijital Kültürün yaygınlaştığı eğitim ortamlarına dönüşümün sağlanması

- Inovasyon güdümlü eğitim programlarının yaşama alınması

- Yeni iş modelleri ve çok disiplinli eğitim programlarının uygulanması (fakültelerin yapılanmasının buna göre gerçekleştirilmesi)

- Akreditasyon süreçlerindeki değişime ayak uydurmak, sabit eğitim programlarından vazgeçmek, inovasyon döngüsüne dayanan eğitim programları

- Yeni eğitim teknolojileri ve yaklaşımlarının kullanılması sanal simülasyon sistemleri (Artırılmış gerçeklik ile gerçek dünyanın entegrasyonu) ile zenginleştirilmiş eğitim programları gibi)

- Uzaktan eğitim teknolojileri ve bilgisayar tabanlı yeni öğrenme süreçlerinin uygulanması

- Kişiselleştirilmiş eğitim ortamlarının devreye alınmasi

\section{SONUÇ}

Toplumsal dönüşümlerin sağlıklı yürüyebilmesi sadece endüstriyel ve teknolojik dönüşümler ile mümkün değildir. Buna paralel olarak eğitim ve sağlık gibi toplumun temel dinamizmini yönlendirecek nitelikteki alanlarda da değişim ve dönüşümün sistematik bir şekilde yürütülmesi temel zorunluluklardandır. Bundan 20-30 sene önce 1 Milyon \$ civarında para ödenerek elde edilecek olan sistemleri bugün 700-800\$ gibi çok küçük bir değere almak söz konusu olmuş ise bunu sağlayan bilgi, birikim, deneyim, teknolojik alt yapı vb. konuların eğitim sisteminin temel taşlarını oluşturması kaçınılmazdır. Bunu gerçekleştiremeyen ülkelerin yeni olanakları elde etmeleri mümkün olmayacaktır. Aksine buna sahip olan ülkeleri izlemek ve onların yönlendirmelerine maruz kalmak durumu kaçınılmaz olacaktır.

Eğitim sistemlerinde bir taraftan büyük veri, implante teknolojiler, dijital gözlük, giyilebilir internet, makinelerin insansız birbirleri ile konuşmasını sağlayan nesnelerin interneti, zeki şehirler ve insansız otonom çalışan fabrikalar, 3 Boyutlu yazıcılar ve eklemeli imalat gibi teknik alanlara odaklanılır iken diğer yandan analitik düşünme, dijital kültür ile barışık olma, entelektüel sermaye yönetimi, fikir bankaları, sosyokültürel olaylara proje ve senaryo bazlı çözümler üretebilme, proaktif olma, kendi eksikliklerini görebilme, gelişmeleri yakından okuyabilme, büyük resme odaklanabilme vb. konularda etkin beyinlerin oluşturulması gerekli olacaktır. Gelecek dünyasının aşağıdaki nitelikleri düşünüldüğünde yukarıda açıklanan Eğitim 4.0 kavramının ülkeler için ayrıca çok stratejik bir konu olduğu net olarak ortaya çıkacaktır.

- Bireysel dijital ordular ve teknoloji polislerinin kullanılmasi

- Yazılım, otonom polisler ve ordularının görevde olmasi

- Teknik altyapı \& enerji - gıdayı hedefleyen savaşların kaçınılmaz olması

- Global siyasete firmaların yön vermeye başlaması

- Hava, su ve bitkiler için otonom kalite kontrolü ve filtreleme sistemlerinin etkin olarak kullanılması

- Otonom sağlık, cerrahi ve yapay organlar hayatın vazgeçilmez bileşenleri arasında yer alması

- Siber destekli zekâ ve hafiza, ilave uzuvlar ile yaşamin kalitesinin artırılması

- Sanal ve gerçeğin karışması neticesinde artırılmış gerçekliğin rutin yaşama dönmesi

- Simülasyon tatiller ve daha az konuşma insan hayatının bir parçası haline gelmesi

Aslında bu listenin daha artırılması mümkündür. Toplumların kaçınılmaz dijital dönüşümü kendileri için en uygun şekilde yaşayabilecekleri bir yol haritası belirleyerek eğitim sistemlerini ona göre yeniden düzenlemeleri gerekmektedir. Robotların gelmesi ile oluşan işsizlik ve teknolojik kölelik gibi kaygıların ortadan kalkması için bu çok önemlidir. Çünkü nasıl eğitim 4.0 anlayışı ile makinalar çıktığında insanların işsiz kalma korkuları boşa çıktı ise, endüstri 4.0 toplumunda da işsizlik ve diğer korkulara yer olmadığı görülecektir. Yeni sistemler geliștirecek, inovatif beyinlere her zaman ihtiyaç olacaktır. Her türlü kötü düşüncenin önüne geçecek sistemlerin geliştirilmesi de mümkün olacaktır. Ancak sağlıklı bir eğitim dönüşümü gerçekleştiremeyen toplumlarda bu korkular kalıcı izler birakacak ve telafisi de eskisi kadar kolay olmayacaktır.

\section{KAYNAKÇA}

Aslangilay A. S., (2016), "Küreselleşme sürecinde inovasyonun önemi ve yükseköğretim kurumlarına düşen görevler", Bolum 10, Eğitim Bilimlerinde yenilikler ve nitelik arayışı, Eds. Demirel Ö, Dincer S., Pegem Akademi, E-ISSN 9786053183563

Bloom B., B. Mesia, and D. Krathwohl (1964). Taxonomy of Educational Objectives (two vols: The Affective Domain \& The Cognitive Domain). New York. David McKay.

Crosier D. and Parveva T., (2013), The Bologna Process: Its impact on higher education development in Europe and beyond, UNESCO: International Institute for Educational Planning, ISBN: 978-92-803-1368-0

Davies R., Coole T., Smith A., (2017), "Review of socio-technical considerations to ensure successful implementation of Industry 4.0", Procedia Manufacturing, 11, pp. 1288 - 1295

Fisk P, (2017), "Education 4.0 ... the future of learning will be dramatically different, in school and throughout life", http://www. 
thegeniusworks.com/2017/01/future-education-young-everyone-taught-together/, (available on 21.01.2018)

Liao Y., Deschamps F., Loures E., Ramos L. (2017), "Past, present and future of Industry 4.0 - a systematic literature review and research agenda proposal", International Journal of Production Research, 55, (12), 3609-3629

Michal Rosík (2017). Education 4.0: Is there a synergy between Industry 4.0 and Education? International Workshop on Knowledge Management, IWKM'2017, 12 - 13 October 2017, Slovakia

Oztemel E., (2017). Endüstri 4.0 ve sosyal etkileri, International Symposium on Indutry 4.0 and Applications (ISIA 2017), 12-14
October 2017, Karabuk University, Karabuk, Turkey, (Invited paper-in Turkish), p. 12

Pooworawan.Y.(2015). Challenges of New Frontier in Learning: Education 4.0. Document by Innovative Learning Center, Chulalongkorn University, Bangkok

Puncreobutr R. (2016) Education 4.0: New Challenge of Learning, St. Theresa Journal of Humanities and Social Sciences, 2(2) July-December 201692

Wallner T., Wagner G., (2016), Academic Education 4.0, International Conference on Education and New Developments, 1214 June 2016, Slovenia, pp. 155-159 